\title{
EDITORIAL
}

\section{Do not jump too quickly to conclusions}

\author{
Daniel B Kopans ${ }^{* 1,2}$ \\ See related research by Nederend et al., http://breast-cancer-research.com/content/14/1/R10
}

\begin{abstract}
A great deal of misinformation has been promulgated about mammography screening. For example, there is no biological or scientific support for the use of the age of 50 years as a threshold for screening. Mammography screening can reduce deaths from breast cancer even if the rate of advanced cancers is not decreased. The suggestion that screening results in massive amounts of overdiagnosis is based upon faulty methodology. The results reported in the recent study by Nederend and colleagues may be due to the screening interval and thresholds used for intervention. What is clear, however, is that they do not show that screening is ineffective.
\end{abstract}

The extreme response to the paper by Nederend and colleagues [1] is that screening for breast cancer is ineffective. This is, of course, not true. Arguments that would deny women access to screening services that have advanced for more than a decade $[2,3]$ have been repeatedly refuted [4-7]. Indeed, more than 40 experts in breast health care have severely criticized these methods as 'scientifically unsound' [8].

The claim that if screening does not reduce the rate of advanced cancers, it is ineffective $[9,10]$ is simply false. Mammography screening saves lives by finding cancers earlier within stages [11]. The fact that Nederend and colleagues did not find a decrease in the rate of advanced cancers in their southern Netherlands screening program does not mean that there will not be a decrease in deaths.

Since a decrease in advanced cancers has been shown to have occurred in randomized, controlled trials [12] and other screening programs [13], including in women aged 40 to 49 years [14], this paper raises questions about

*Correspondence: dkopans@partners.org

'Harvard Medical School, 25 Shattuck Street, Boston, MA 02115, USA

${ }^{2}$ Breast Imaging Division, Department of Radiology, Massachusetts General

Hospital, Avon Comprehensive Breast Center, Suite 240, 15 Parkman Street, Boston, MA 02114, USA the screening program employed, not about screening per se. The reasons for this are multifactorial.

First, they may have overlooked an actual decrease. The rate of advanced cancers reached almost 180 out of 100,000 before screening, and dropped over the screening period to 160 out of 100,000 for most of the years after screening began. In addition, the background rate of advanced cancers increased by almost $50 \%$ over the period among women who were not offered screening. Thus, the baseline for comparison was actually increasing, yielding screened women a relative decrease in advanced cancers.

Second, as an economic measure, many European screening programs screen only every 2 or more years. Periodic screening is not expected to have much effect on the fastest growing cancers (length bias). Interrupting moderate and even slower growing cancers save lives. The Swedish Two-County trial shows that mortality reduction begins about 5 to 7 years after the start of screening with decreased deaths occurring over more than 20 years [15].

Third, in this Netherlands' study a large number of the advanced cancers were detectable 2 years earlier. With annual screening, many of these - as well as some that were not evident 2 years earlier - might have been detected a year earlier at a smaller size and earlier stage.

Fourth, these results could also be due to the high threshold for intervention used by the radiologists. Many of the cancers were evident on the falsely negative screen 2 years earlier. With a lower threshold, these might have been diagnosed 2 years earlier and have been less advanced. In the US, where lower thresholds for intervention and higher recall rates have been criticized, there was a clear association between the onset of screening in the mid-1980s and the decline in breast cancer deaths that began in 1990 (for the first time in 50 years) [16], fulfilling the criterion by Autier and colleagues [17].

Fifth, the suggestion by some that 30 to $50 \%$ of cancers found by screening would 'melt away' had they not been found by mammography is, in my view, based upon faulty methodologies [18]. Accurate estimates of 'overdiagnosis' can only come from randomized, controlled trials and these suggest overdiagnosis rates that are less than $10 \%$, and likely lower than $1 \%$ [19]. If overdiagnosis is as 
common as opponents would have us believe, why is there not one published series documenting breast cancers that have 'melted away' in the absence of therapy?

Sixth, when cancers are found earlier the mastectomy rate is lower, not higher [20], even among women aged 40 to 49 years [21]. Importantly, the authors failed to adjust for lead time, new prevalence cancers being added each year, or the increasing baseline incidence of breast cancer. The authors should also have looked at the mastectomy rates as a function of time period, since therapy has changed over time. Many lesions that used to be treated by mastectomy in the past are no longer treated in this manner.

Despite its suggested failure to reduce advanced cancers, the Netherlands screening program will, likely, still show a decrease in deaths. Medical oncology groups have not joined with recent efforts to reduce the use of mammography screening for one principal reason: because they know that therapies only save lives when breast cancers are found earlier.

\section{Competing interests}

The author declares that they have no competing interests.

Published: 23 July 2012

\section{References}

1. Nederend J, Duijm LEM, Voogd AC, Groenewoud JH, Jansen FH, Louwman MWJ: Trends in incidence and detection of advanced breast cancer at biennial screening mammography in The Netherlands: a population based study. Breast Cancer Res 2012, 14:R10.

2. Gotzsche PC, Olsen O: Is screening for breast cancer with mammography justifiable? Lancet 2000, 355:129-134.

3. Gøtzsche PC: Time to stop mammography screening? CMAJ 2011, 183:1957-1958.

4. Freedman DA, Petitti DB, Robins JM: On the efficacy of screening for breast cancer. Int J Epidemiol 2004, 33:43-55.

5. Knottnerus JA: Report to the Minister of Health, Welfare, and Sport: The Benefit of Population Screening for Breast Cancer with Mammography. Publication No. 2002/03E. The Hague: Health Council of the Netherlands; 2002.

6. Duffy SW, Tabar L, Smith RA: The mammographic screening trials: commentary on the recent work by Olsen and Gotzsche. CA Cancer J Clin 2002, 52:68-71.

7. Kopans DB: The most recent breast cancer screening controversy about whether mammographic screening benefits women at any age: nonsense and nonscience. AJR Am J Roentgenol 2003, 180:21-26

8. Effect of population-based screening on breast cancer mortality [http://mammographyed.com/docs/LancetLetter.pdf]

9. Esserman L, Shieh $Y$, Thompson I: Rethinking screening for breast cancer and prostate cancer. JAMA 2009, 302:1685-1692.

10. Gøtzsche PC, Jørgensen KJ, Zahl PH, Mæhlen J: Why mammography screening hasn't lived up to expectations from the randomised trials. Cancer Causes Contr 2012, 23:15-21.

11. Chu KC, Connor RJ: Analysis of the temporal patterns of benefits in the Health Insurance Plan of Greater New York trial by stage and age. Am J Epidemiol 1991, 133:1039-1049.

12. Autier P, Héry C, Haukka J, Boniol M, Byrnes G: Advanced breast cancer and breast cancer mortality in randomized controlled trials on mammography screening. J Clin Oncol 2009, 27:5919-5923.

13. Coburn NG, Chung MA, Fulton J, Cady B: Decreased breast cancer tumor size, stage, and mortality in Rhode Island: an example of a well-screened population. Cancer Control 2004, 11:222.

14. Malmgren JA, Parikh J, Atwood MK, Kaplan HG: Impact of mammography detection on the course of breast cancer in women aged $40-49$ years. Radiology 2012, 262:797-806.

15. Tabár L, Vitak B, Chen TH, Yen AM, Cohen A, Tot T, Chiu SY, Chen SL, Fann JC, Rosell J, Fohlin H, Smith RA, Duffy SW: Swedish two-county trial: impact of mammographic screening on breast cancer mortality during 3 decades. Radiology 2011, 260:658-663.

16. Kopans DB: Beyond randomized, controlled trials: organized mammographic screening substantially reduces breast cancer mortality. Cancer 2002, 94:580-581.

17. Autier P, Boniol M, Gavin A,Vatten LJ: Breast cancer mortality in neighbouring European countries with different levels of screening but similar access to treatment: trend analysis of WHO mortality database. BMJ 2011, 343:doi:d4411(Published 28 July 2011).

18. Kopans DB, Smith RA, Duffy SW: Mammographic screening and "overdiagnosis". Radiology 2011, 260:616-620.

19. Duffy SW, Agbaje O, Tabar L, Vitak B, Bjurstam N, Björneld L, Myles JP, Warwick $\mathrm{J}$ : Overdiagnosis and overtreatment of breast cancer: estimates of overdiagnosis from two trials of mammographic screening for breast cancer. Breast Cancer Res 2005, 7:258-265.

20. Responses to 'Effect of mammography screening on surgical treatment for breast cancer in Norway: comparative analysis of cancer registry data' [http://www.bmj.com/content/343/bmj.d4692?tab=responses]

21. Paci E, Duffy SW, Giorgi D, Zappa M, Crocetti E, Vezzosi V, Bianchi S, Cataliotti L, del Turco MR: Are breast cancer screening programmes increasing rates of mastectomy? Observational study. BMJ 2002, 325:418.

doi:10.1186/bcr3213

Cite this article as: Kopans DB: Do not jump too quickly to conclusions.

Breast Cancer Research 2012, 14:108. 